\title{
RODÍZIO DE FIRMAS DE AUDITORIA: A EXPERIÊNCIA BRASILEIRA E AS CONCLUSÕES DO MERCADO
}

\author{
ROTATION OF AUDIT FIRMS: THE BRAZILIAN \\ EXPERIENCE AND THE MARKET'S CONCLUSIONS
}



Alexandre Queiroz de Oliveira

Professor Mestre do Departamento de Ciências Contábeis da Faculdade São Luis - SP e mestre em Ciências Contábeis e Atuạriais pela Pontifícia Universidade Católica de São Paulo - SP.

E-mail: aq.oliveira@terra.com.br

\author{
Neusa Maria Bastos Fernandes dos Santos \\ Professora Titular da Pontifícia Universidade Católica de São Paulo \\ Mestre em Administração e doutora em Controladoria e Contabilidade \\ pela Faculdade de Economia e Administração \\ da Universidade de São Paulo - SP \\ E-mail: admneuza@puc.sp.br
}

\section{RESUMO}

O rodízio de firmas de auditoria foi introduzido no Brasil por ocasião dos escândalos corporativos de instituições financeiras na emissão das demonstrações contábeis e adotado pela CVM - Comissão de Valores Mobiliários às empresas registradas na Bolsa de Valores do Brasil: Tendo como objetivo a preservação da independência do auditor e a diminuição dos erros contábeis e fraudes relacionados ao processo de auditoria das demonstrações contábeis, o rodízio de firmas é um assunto polêmico, pois afeta a relação comercial e profissional dos auditores com seus clientes bem como toda a estrutura de mercado das firmas de auditoria. $\mathrm{O}$ artigo foi desenvolvido com base na evolução histórica do conceito de rodízio de firmas de auditoria, na avaliação das pesquisas realizadas sobre $\mathrm{o}$ assunto em outros países e nas estruturas filosóficas que determinam os princípios éticos que são atrelados à Contabilidade e à Auditoria. Além disso, foi realizada uma pesquisa de campo sobre os aspectos inerentes do rodízio de firmas de auditoria. Essa pesquisa coletou a opinião de 127 profissionais do mercado financeiro, sendo 84 executivos de empresas que trabalham ou influenciam na elaboração das demonstrações contábeis e 43 auditores independentes que atuam diretamente no processo de auditagem das contas contábeis. A principal conclusão obtìda foi a confirmação de que o rodízio de firmas de auditoria não tem capacidade de assegurar a independência do auditor no seu trabalho e não diminui os riscos de erros contábeis e de fraudes na elaboração das demonstrações contábeis.

Palavras-chave: Rodízio de firmas de auditoria. Independência do auditor. Erros contábeis e fraudes. Elaboração das demonstrações contábeis.

\section{ABSTRACT}

The rotation of audit firms was introduced in Brazil as a result of the corporate scandals involving financial institutions in the issue of their financial statements, and adopted by the CVM-Brazilian Securities Commission for publicly traded companies in Brazil. Aiming to preserve the independence of the auditor and to reduce frauds and accounting errors and misstatements of financial statements, audit firm rotation affects the commercial and professional relationship of the auditors with their clients, as well as the whole structure of the audit firm market. The article was prepared on the basis of the historical concept of audit firm rotation, the evaluation of the surveys carried out on the subject in other countries, and the philosophical structures that determine the ethical principles associated to audits. Furthermore, a field survey was carried out on aspects related to audit firm rotation. This survey collected the opinions of 127 financial market professionals, 84 of whom were executives from companies that work on or influence the preparation of financial statements, and 43 independent auditors who work directly in the accounting record auditing process. The main conclusion was the confirmation that audit firm rotation cannot ensure the independence of the auditor in his work, nor does it diminish the risks of accounting errors or frauds in the financial statement preparation.

Keywords: Audit firm rotation. Independence of the auditor. Frauds and accounting misstatements. Preparation of financial statements. 


\section{INTRODUĈ̣̃O}

Em dezembro de 2005, após 3 anos de experiência, o Conselho Monetário Nacional decidiu suspender os efeitos do rodízio de firmas de Auditoria para Instituições Financeiras para exames de auditoria a serem realizados nos exercícios a findar em dezembro de 2006 e de 2007.

A Resolução no 3.332, do Conselho Monetário Nacional, determinou

Suspender, até 31 de dezembro de 2007, a obriga-

toriedade prevista no art. $9^{\circ}$. Do Regulamento anexo à Resolução 3.198, de 27 de maio de 2004, relativa à substituição periódica do auditor independente contratado pelas instituições financeiras[...]

Instituída após a comprovação de falha nos exames das demonstrações contábeis de Instituições Financeiras na década de 80 , a substituição periódica e obrigatória de auditores, no Brasil, passou a ser requerida pelo BACEN - Banco Central do Brasil e pela CVM - Comissão de Valores Mobiliários, no intuito de atenuar a falta de credibilidade que o mercado financeiro passou a apresentar com a descontinuidade das instituições financeiras e também pelos prejuízos financeiros gerados a diversos correntistas. Assunto polêmico, foi amplamente discutido pelo mercado, com posições favoráveis e desfavoráveis, entretanto, a nova decisão do Banco Central é conseqüência da experiência de três anos do sistema no mercado financeiro e carece, como mencionado na referida Resolução, de uma nova avaliação.

$A$ atuação do auditor independente no âmbito do mercado de valores mobiliários passou a ser discutida no Brasil e foi incrementada com as evidências de fraudes e de escândalos corporativos nos Estados Unidos e na Europa. O desaparecimento prematuro da firma de Auditoria Arthur Andersen e os erros dos trabalhos de auditoria sobre as demonstrações contábeis das entidades americanas, ocasionaram uma grande intervenção do governo americano no mercado de valores mobiliários. Como enfatiza Vampel (2004), para responder aos escândalos corporativos que abalaram os mercados de capitais do mundo inteiro, o governo americano promulgou a Lei Sarbanes-Oxley (SOX) para dar maior credibilidade ao mercado de capitais.

Destaque-se a posição do General Accounting Office $(G A O)^{\prime}$ que concluiu para o mercado americano que " $a$ ação em curso mais prudente neste momento é para a SEC - Securities Exchange Commission e para o PCAOB - Public Accounting Oversight Board ${ }^{3}$ seria monitorar e avaliar a efetividade dos requerimentos da Lei Sarbanes-Oxley (SOX) no que tange à melhoria da independência do auditor $e$ da qualidade da auditoria" e, portanto, atrasar o rodízio obrigatório de firma até que as reformas produzidas pela SOX pudessem ser avaliadas. O posicionamento mencionado ocorreu em 2003 e, apesar de o rodízio obrigatório de firmas não ter sido recomendado, o GAO sugeriu, entretanto, que tal procedimento se tornará necessário se a Lei Sarbanes-Oxley não aumentar a qualidade da auditoria.

Por ser uma atividade em que a confiança entre cliente e auditor é conquistada de forma lenta, a auditoria independente tem sido caracterizada por relacionamentos comerciais de longo prazo com seus clientes. Nesse pressuposto, a CVM - Comissão de Valores Mobiliários (2004) justificou o rodízio de firmas no seguinte contexto "quando uma auditoria trabalha por muito tempo na mesma empresa, é natural uma acomodação".

Chung (2004) relata que a função da auditoria independente é muito importante no mercado de capitais, pois proporciona proteção aos interesses do investidor, requerendo que as firmas de auditoria sejam independentes do seu cliente e atuem em nome da sociedade. Entretanto, o controle sobre a contratação e a troca de auditores está sob a responsabilidade da administração do cliente que, combinada com a forte motivação da administração na obtenção de melhores desempenho e resultado, impõe sobre o auditor uma forte pressão a respeito dos resultados dos trabalhos de auditoria.

O presente estudo visa elucidar a experiência brasileira com o rodízio de firmas de Auditoria, ressaltando a sua historia e confirmar quais são os principais aspectos que auditores e executivos de empresas ressaltam em um trabalho de auditoria. Em pesquisa realizada com 127 executivos, representados por 43 auditores externos com experiência média de 10 anos de auditoria de empresas nacionais e internacionais e 84 executivos de empresas nacionais e internacionais, em funções de Controladoria, Contabilidade e Diretoria Financeira, foram obtidas opiniões importantes a respeito dos trabalhos de auditoria efetuados no mercado e os principais efeitos do Rodízio de Firmas de Auditoria. A pesquisa acrescenta aspectos conceituais sobre o impacto do rodízio de firmas na carreira de auditores e na estrutura de firmas, fornecendo detalhes sobre o relacionamento específico entre clientes e auditores. Porém, o objetivo maior é o de comprovar os limites da independência do trabalho de auditoria e a responsabilidade do auditor no contexto das fraudes corporativas. O rodízio de firmas é capaz de preservar a independência do auditor e evitar fraudes no exame de auditoria das demonstrações contábeis das empresas?

Este estudo está dividido em 8 seções. Após a introdução, é apresentado um breve histórico internacional do rodízio de firmas. Na seção seguinte, são fornecidos os princípios filosóficos que regem a Contabilidade e a Auditoria Independente. Na quarta seção, são apresentadas as características das fraudes corporativas e a responsabilidade dos auditores na sua detecção. A seção cinco relata os aspectos negativos e positivos do rodízio de firmas de auditoria. A seção seis apresenta as pesquisas internacionais relacionadas com a substi-

\footnotetext{
I General Accounting Office: Departamento Geral de Contabilidade Norte-Americano.

2 Securities Exchange Commission: Comissão de Valores Mobiliários dos Estados Unidos.

3 Public Company Accounting Oversight Board: Orgão revisor das firmas de auditoria que prestam serviços às empresas listadas na Bolsa de Valores dos Estados Unidos.
} 
tuição obrigatória dos auditores independentes e a opção de diversos países entre o rodízio de profissionais e o rodízio de firmas. Na seção 7, são apresentados os resultados da pesquisa efetuada com executivos de empresas e com os auditores independentes. Resumida em quadros, a pesquisa aborda va- riáveis importantes na extensão dos trabalhos de um exame de auditoria e, por fim, na seção 8 , é feita a conclusão do estudo, compilando todas as informações necessárias para fundamentar a resposta à pergunta do estudo.

\section{HISTÓRICO DO RODÍZIO DE FIRMAS DE AUDITORIA}

Chew (2003) em seu estudo sobre a história do rodízio de firmas de Auditoria, menciona que, no início do século $X X$, as práticas britânicas de contabilidade e de auditoria tinham grande influência sobre o mercado americano. Não obstante um número extenso de fraudes em corporações inglesas, com os casos "Leeds Estate Building and Investments Co"., "The Kingston Cotton Mill Company em 1896 e Rex v Kylsant em I93 I", a estabilidade do auditor não havia sido questionada, apesar de suspeitas.

Algumas companhias consideraram os benefícios da mudança de auditores externos como uma forma de buscar mais valor do que foco em seus custos. De fato, a maior empresa americana, E. I. DuPont de Nemours E Company (DuPont), começou a adotar como política o processo de mudar seus auditores e procedeu ao rodízio de auditores a cada ano, no período de 1911 até 1927, exceto em 1919. Em 1928, a companhia alterou sua política e experimentou ter um mesmo auditor por anos consecutivos. A rotação periódica aconteceu até 1954, quando a DuPont decidiu apontar um único auditor independente de forma permanente.

Outro caso destacado por Chew (2003), em 1939, o caso McKesson e Robbins foi o primeiro exemplo em que as práticas de auditoria foram publicamente criticadas e julgadas. O caso envolveu uma fraude do seu ex-presidente e de seus três irmãos para fraudar a companhia. Eles elaboraram um esquema com empresas fictícias, estoques inexistentes e forjaram uma variedade grande de documentos. Quando a fraude foi descoberta, constatou-se que havia ocorrido um desvio de aproximadamente US\$2,9 milhões do caixa da companhia em um período de 12 anos.

Em razão da falta de dois procedimentos de auditoria, o primeiro, a observação física dos estoques e o segundo o de se obter a confirmação de contas a receber, naquela oportunidade procedimentos de auditoria ainda não requeridos, o auditor independente não detectou o montante de US\$19 milhões de ativos não existentes e US\$ I,8 miIhões de vendas fictícias. Em conseqüência, o rodízio de firmas passou a ser discutido e, ao final do processo de avaliação, o acompanhamento de inventários físicos e de confirmação de saldos passaram a ser procedimentos obrigatórios em um trabalho de auditoria.

$\mathrm{Na}$ década de 70 , graças ao aumento da competitividade entre as firmas de auditoria, o debate sobre o rodízio foi iniciado e Chew (2003) enfatiza que, em 1976, dois eventos contribuíram para incitar novamente a discussão: primeiro, a tentativa no Senado Federal dos Estados Unidos, na Comissão de Direitos e Responsabilidades Corporativas, de adotar o rodízio a cada cinco anos para as empresas listadas em Bolsa de Valores. Não houve sucesso nessa petição.

O segundo evento foi precipitado pelo apoio à rotação de firmas de auditoria na Subcomissão do Senado Federal para Relatórios de Auditoria e da Administração. O senador Lee Metcalf, em seus estudos, menciona a existência de erros, falhas corporativas e dificuldades financeiras não informadas pelas grandes empresas ao mercado.O relatório final sobre diversos temas contábeis, em suas 16 recomendações, propõe na recomendação $n^{\circ} 4$, a adoção do rodízio de firmas. Em resposta, o AICPA ${ }^{4}$ contestou o procedimento, abordando a possibilidade de aumento de custos para as empresas e enfatiza que o rodízio de profissionais e a adoção de comitê de auditoria seriam suficientes para monitoramento do assunto.

\section{A ÉTICA NA AUDITORIA E NA CONTABILIDADE}

Lisboa (1 997) conceitua a ética como "os princípios de conduta que norteiam um indivíduo ou grupo de indivíduos". No mesmo contexto, Sá (200I) afirma que a ética tem ligações muito fortes com as doutrinas mentais e espirituais, pois, em verdade, são fontes de conhecimentos que interessam diretamente à análise das virtudes. Ressalta que os estudos científicos da mente confirmam a influência dos conhecimentos adquiridos nas primeiras idades em relação às estruturas dos pensamentos, logo, das ações. E que seria na convivência com seus semelhantes, que ainda crian- ça tende a absorver deles, por imitação ou recalque, o que Ihe desagrada ou causa mal-estar. Seria, nessa fase, que as primeiras noções sobre as virtudes que sustentam os princípios éticos são estimuladas.

O filosofo Aristóteles, em Ética a Nicômaco (2004), ressalta que as virtudes éticas são atitudes controladoras e formadoras das emoções, duradouramente atuantes; são atitudes consolidadas e hábitos de ação que são desenvolvidas por meio do exercício e da repetição. Nesse condicionante, o comportamento das pessoas seria fortemente 
influenciado pelas condições que cada uma tem a seu redor, da mesma forma que pelas informações adicionais que recebe pela vida afora. Tal fato ocorre porque a visão de vida de cada pessoa está totalmente dirigida por aquelas condições e informações.

Ferrel, Fraedrich e Ferrel (2000) ressaltam os principais fundamentos das teorias filosóficas: aquelas que dimensionam problemas éticos nos negócios e na contabilidade estão abordadas no egoísmo, no utilitarismo e na deontologia.

Os egoístas acreditam que devem tomar decisões que maximizem seu próprio interesse, que cada indivíduo define de maneira diferente. Já a ética utilitarista é voltada para a reforma da sociedade e a distribuição de justiça eqüitativa para todos os homens, o utilitarismo converteu-se em princípio metodológico das ciências sociais. Sua ligação com a Contabilidade e com a Auditoria reside na utilidade que as demonstrações contábeis têm para a comunidade e para o mercado.

Divergindo dos utilitaristas, os deontologistas argumentam que há certas coisas que não se devem fazer, nem mesmo para maximizar a utilidade. A deontologia moderna foi muito influenciada pelo filosofo alemão Immanuel Kant (2004), que formulou o chamado "imperativo categórico": "age de tal modo que a norma da tua conduta possa ser tomada como lei universal".

Analisando a deontologia, Sá (2001) enfatiza que as relações de valor que existem entre o ideal moral traçado e os diversos campos da conduta humana podem ser reunidas em um instrumento regulador. Tal conjunto racional, com o propósito de estabelecer linhas ideais éticas, já é uma aplicação da ciência ética, que se consubstancia em uma peça magna, como se fosse uma lei entre partes pertencentes a grupamentos sociais: "uma espécie de contrato de classe gera o Código de Ética Profissional e os órgãos de fiscalização do exercício passam a controlar a execução de tal peça magna”.

No campo da auditoria, Boynton, Johnson e Kell (2002) ressaltam que a independência é o alicerce da estrutura filosófica da profissão de auditoria e que opinião do auditor teria pouco valor para aqueles usuários que devem confiar em seu parecer se os auditores não forem independentes.

O AICPA conceitua a independência como "agir com integridade e com objetividade". Segundo essa entidade, os auditores precisam ser independentes na aparência, não devem ter interesses financeiros nem relações de negócios importantes com os clientes, não devem participar da administração nem do conselho de administração do cliente, e sempre devem avaliar, na sua prática profissional, as relações com seus clientes, para evitar situações que possam prejudicar sua independência. Ao prestar serviços de auditoria e outros serviços, o auditor deve ser independente: de fato e na aparência.

Conceito de integridade é definido por Boynton, Johnson e Kell (2002) como uma característica pessoal indispensável em um auditor, referencial no julgamento de todas as decisões tomadas em um trabalho. Também é a qualidade na qual a confiança pública se baseia. Para que atendam a esse princípio, os auditores devem ser honestos e sinceros. Integridade permite erros não intencionais e diferenças legítimas de opiniões, mas não tolera distorção intencional de fatos ou subordinação de julgamento.

A objetividade é um estado mental; embora não mensurável, esse princípio é indispensável para os que atuam com auditoria independente. Objetividade significa ser imparcial, não ser tendencioso, em todas as questões relacionadas a um trabalho. A obediência a esse princípio aumenta quando os membros evitam circunstâncias que envolvem conflitos de interesse.

\section{A AUDITORIA INDEPENDENTE E AS FRAUDES CORPORATIVAS}

O conceito de fraudes apresenta uma dimensão bastante ampla. O SAS (Statement on Auditing Standard) $\mathrm{n}^{\circ}$ 82. "Consideração de fraude em uma auditoria contábil" (Consideration of Fraud in a Financial Statement Audit), estabelece que o interesse do auditor se relaciona especificamente a atos fraudulentos que provoquem distorções relevantes nas demonstrações contábeis. Essas distorções são divididas em dois tipos: (i) aquelas relativas à preparação fraudulenta de demonstrações contábeis e (ii) as referentes à apropriação indébita de ativos.

A responsabilidade do auditor pela detecção de fraudes ou de erros não intencionais concerne ao planejamento da auditoria de forma tal que obtenha segurança razoável de que as demonstrações contábeis não contêm distorções relevantes causadas por erro ou fraude. $\mathrm{O}$ auditor deve avaliar no planejamento o risco de fraude.

As normas de auditoria brasileiras apresentam-se. harmonizadas em relação às normas internacionais e americanas no que concerne ao tema da fraude. Dentro de sua estrutura conceitual, determina procedimentos de auditoria que devem ser realizados e enfatiza a responsabilidade da administração na prevenção e na identificação de fraudes mediante a manutenção de um sistema de controles internos.

Apesar de o trabalho em auditoria não ser voltado necessariamente para a descoberta de fraudes, o tema foi objeto de pesquisa recente pela firma de Auditoria KPMG (2004). Em sua terceira edição, o relatório da pesquisa de 2004 sobre "A Fraude no Brasil" ressalta que os controles internos deficientes permitiram a ocorrência de fraudes e as organizações estão-se concentrando em métodos internos de detecção de fraudes, em treinamento de pessoal e no estabelecimento de um código de conduta ou de comportamento profissional. A constatação de fraudes é, em sua grande maioria, feita pela auditoria interna (39\%) e pelos controles internos (52\%). A auditoria independente apareceu em apenas $2 \%$ das citações.

A pesquisa "2004 Report to the Nation on Occupational Fraud and Abuse", elaborada pela Association of Certified Fraud Examiners, ressalta, em seu sumário executivo, a utilização dos Comitês de Auditoria como canalizadores do 
recebimento desses relatórios confidenciais demandados por avisos anônimos de funcionários sobre operações fraudulentas nas organizações, além da constatação de que esse procedimento é mais eficiente que a prática de auditoria independente e até mesmo de auditoria interna.

O dilema sobre a responsabilidade de identificar fraudes pelos auditores independentes é abordado por Antunes (1 998) que menciona a mudança de visão dos auditores, ao longo do tempo, com relação a fraudes. Antes de 1900, a detecção de fraudes era um dos objetivos primários da atividade de auditoria. Em 1912, Montgomery, em sua obra Auditing Theory and Practice, constatava que a deteç̧ão de fraudes era um objetivo menor do trabalho dos auditores independentes.

Nepomuceno (2002) ressalta que, em 1933, quando o Congresso Americano analisava a Lei de Ações, houve uma proposta para submeter as demonstrações contábeis aos auditores do Governo, em vez de aos auditores independentes. Com efeito, entre 1940 e 1950, os auditores não tinham nenhuma responsabilidade de identificar fraudes.
Em I95I, as publicações do AICPA indicavam que a auditoria não era projetada para descobrir irregularidades.

Nos anos 60, tais publicações consideravam que os auditores assumiam alguma responsabilidade na detecção, no caso de suspeitas de eventos que estimulassem as fraudes. A SAS - 16, The Independent Auditor's Responsibility for the Detection of Errors or Irregularities, publicada em 1977, esclarecia que o auditor tinha a responsabilidade de pesquisar irregularidades relevantes. Em 1988, a SAS (Statement on Auditing Standard) 53 obrigou os auditores a avaliarem o risco de fraude e planejarem a auditoria para prover razoável segurança na detecção desses riscos. Em fevereiro de 1997, a SAS - 82 - Consideration of Fraud in a Financial Statement Audit, que determinava que o "auditor tem a responsabilidade de planejar e desenvolver a auditoria para obter razoável segurança de que as demonstrações financeiras estão liures de classificações indevidas relevantes, ocasionadas por erros ou fraudes".

\section{ASPECTOS POSITIVOS E NEGATIVOS DO RODÍZIO DE FIRMAS}

Em pronunciamentos específicos, o AICPA (1992) e o IBRACON, (2003) se posicionaram contra o rodízio de firmas de auditoria. Além disso, as pesquisas internacionais sobre o tema descrevem os principais aspectos negativos e positivos sobre o rodízio de firmas que são apresentados no quadro $\mathbf{O}$

\section{Aspectos negativos}

a) Não mantém o conhecimento acumulado da firma de auditoria que tem feito os trabalhos. O foco dos trabalhos do novo auditor pode não ser direcionado para áreas de risco;

b) Desestabiliza a relação econômica entre as partes. No primeiro ano de trabalho, é realizado um investimento considerável pelas firmas na expectativa de ser recuperado em anos subseqüentes por trabalhos mais eficientes e mais bem planejados;

c) Redução dos investimentos em especialização dos auditores, pois as firmas não alocariam recursos na formação técnica, sem a certeza de que a interrupção do relacionamento ocorreria por circunstâncias normais, e não por decisão regulatória;

d) A governança corporativa é afetada, pois liberdade de escoIha estaria sendo impactada em sua essência;

e) Desequilibra o mercado das firmas pois a busca pela recomposição de carteiras de clientes, seria estruturada de forma inadequada, sem respeitar as condições normais de mercado;

f) A carreira em auditoria seria dificultada, pois a perda desses clientes pode propiciar até mesmo a interrupção da prática de auditoria de firmas.

\section{Aspectos positivos}

a) Socializa o conhecimento técnico pois quebra o monopólio do conhecimento e da prática de auditoria de determinado segmento;

b) Satisfaz o público com a quebra de relacionamento de longo prazo, conferindo a determinados usuários de demonstrações contábeis uma percepção de maior independência;

c) Muda o perfil do auditor nas empresas submetidas ao rodízio. Um perfil mais técnico do auditor é privilegiado em detrimento do perfil comercial e gerador de novos trabalhos;

d) Requer maior atenção do auditor pelo processo freqüente de troca, pela exposição de seus papéis de trabalho a outros auditores, sucessores ou revisores;

e) Focaliza a atenção do auditor no acionista, e não na administração.

f) Muda a metodologia de auditoria com foco concentrado nos procedimentos obrigatórios e maior objetividade na alocação e no foco dos testes de auditoria.

g) Atenua a falta de fiscalização do Estado pois a possibilidade de o auditor sucessor ter acesso aos papéis de trabalho referentes ao processo de auditoria das demonstrações contábeis das empresas pode ser considerada uma forma de fiscalização adicional, que deveria estar sendo feita pelo Estado. 


\section{PESQUISAS REALIZADAS E A POSIÇÃO INTERNACIONAL DO RODÍZIO}

$\mathrm{Na}$ Itália, a pesquisa desenvolvida pela Universidade de Bolonha, SDA Universitá Bocconi, sobre os efeitos do rodízio de firmas de auditoria no mercado de capitais, chamada de "The impact of mandatory audit rotation on audit quality and on audit pricing: the case of Italy" foi realizada com empresas listadas na Bolsa de Valores e visa identificar as bases empíricas dos possíveis impactos do rodízio de firmas de auditoria, introduzido em 1975.

Os resultados dessa pesquisa, emitidos em 2002, demonstraram uma grande concentração do mercado pelas grandes firmas de auditoria e que as normas de rodízio não davam às pequenas e às médias firmas de auditoria oportunidade de competir com as grandes firmas. Além disso, foi confirmado um impacto significativo nos custos de serviços de auditoria nos primeiros anos do trabalho, pois mais horas seriam necessárias para realização dos trabalhos e staff mais qualificado em relação a trabalhos de auditoria de demonstrações contábeis considerados rotineiros. Foi confirmado que os erros nos pareceres foram cometidos no primeiro ano de relacionamento do novo auditor, quando ele ainda não tinha todo o conhecimento requerido para auditar a companhia. A pesquisa confirma que o rodízio de firmas tem um impacto negativo na qualidade dos trabaIhos durante o primeiro ano do serviço.

Constatou-se, também, que existe uma freqüência muito grande de pareceres qualificados com ressalvas a partir do terceiro ano de relacionamento, quando se presume que as firmas de auditoria adquirem um conhecimento profundo a respeito da entidade auditada.

Nos Estados Unidos, em novembro de 2003, o Congresso dos Estados Unidos encomendou ao Departamento Geral de Contabilidade Norte-Americano, conhecido como GAO - General Accounting Office, um relatório para avaliar se o rodízio de firmas de auditoria seria uma medida adequada para evitar fraudes contábeis.

Após um ano de estudo, o GAO decidiu não recomendar o rodízio de firmas, por considerar que os benefícios ainda seriam difíceis de prever e quantificar, ao passo que os custos para as companhias certamente aumentariam.

Os resultados confirmaram que a troca de auditorias aumenta o risco de falhas nos primeiros anos após a mudança, em razão da falta de conhecimento das operações da companhia, do ambiente de sistemas internos e das práticas financeiras. As firmas, também, afirmaram que o custo dos honorários subiria cerca de $20 \%$ em virtude do conhecimento a ser adquirido em cada novo cliente. Ainda, o estudo confirmou que, aos olhos dos investidores individuais, o rodízio de firmas seria positivo. A concorrência no mercado seria afetada, com as firmas acreditando que o mercado de auditoria de empresas abertas se tornaria mais concentrado em um pequeno número de firmas de auditoria.

O prazo de dois a três anos foi estabelecido pelos auditores pesquisados como ideal para obter o conhecimento da estrutura operacional e dos processos do novo cliente e, conseqüentemente, aprofundar e desenvolver uma auditoria mais eficaz.

$\mathrm{Na}$ Inglaterra, em 29 de janeiro de 2003, o grupo denominado Co-ordinating Group on Audit and Accounting Issues (CGAA) emitiu o relatório final sobre a revisão dos procedimentos e políticas empregadas no Reino Unido no que tange à atividade de auditoria independente.

O relatório final reconheceu que, sejam quais forem os efeitos reais do rodízio sobre a independência dos auditores, ele teria em si a virtude de melhorar a percepção de independência e, portanto, de ampliar a confiança no trabalho do auditor. A explicação estaria no fato de que é freqüente a suspeita de que relacionamentos mais longos com o auditor podem gerar acomodação, menos rigor na análise e perda do sentimento crítico na apuração dos números. Entretanto, esse mesmo grupo identificou que, com o aumento da complexidade dos negócios nas grandes empresas, os auditores podem levar anos para compreender plenamente uma empresa ou as operações dessa empresa; dessa forma, o rodízio poderia ampliar os riscos de falhas decorrentes desse aprendizado. Ademais, foi salientada a falta de exemplos de sucesso dessa prática na comunidade internacional.

O relatório final não recomenda o rodízio de firmas e solicita a adoção do rodízio de sócios a cada cinco anos e de outros sócios-chave para o processo a cada sete anos.

No contexto internacional, o procedimento de rodízio de auditores independentes tem sido debatido em vários ambientes de negócio, porém com aplicação concreta extremamente restrita.

Nos Estados Unidos da América, como exemplo de ambiente de negócio e profissional de alto desenvolvimento, o debate do assunto iniciou-se na década de 1930, sendo subseqüentemente rediscutido com certa periodicidade. Porém, a adoção do procedimento de rodízio de firmas de auditoria nesse país tem sido reiteradamente rejeitada. Recentemente, em setembro de 1996, a "General Accounting Office” (agência do governo americano), decidiu novamente, de forma expressa, não recomendar esse procedimento.

Quanto à América do Sul, esse procedimento foi aplicado no Peru e limitado às instituições financeiras. Contudo, em setembro de 1997, esse procedimento foi alterado, sendo agora somente requerido o rodízio da equipe de Auditoria a cada cinco anos, e não mais o rodízio de firma de Auditoria. Esse procedimento está em linha com as regras sobre rodízio de auditores adotadas na Argentina.

No contexto europeu, a Grécia, a Espanha e a Itália adotaram a rodízio de firmas de Auditoria; porém, a Grécia a aboliu em 1994 e, no caso da Espanha, esse procedimento foi abandonado em 1995, não chegando a ser adotado, e a Itália estuda sua eliminação, no contexto da Comunidade Econômica Européia.

Da mesma maneira, a Turquia, também, abandonou esse procedimento em 1998, justificando essa decisão pelo fato de não ser adotado nas economias mais desenvolvidas. 


\begin{tabular}{|l|c|c|}
\hline \multicolumn{1}{|c|}{ País } & Rodízio de profissionais & Rodízio de Firmas \\
\hline Estados Unidos & Sim & Não \\
\hline Reino Unido & Sim & Não \\
\hline Itália & Não & Sim \\
\hline Brasil & Sim & Sim \\
\hline Cingapura & Sim & Sim \\
\hline Áustria & Não & Sim \\
\hline França & Sim & Não \\
\hline Espanha & Sim & Abandonou \\
\hline Holanda & Sim & Não \\
\hline Japão & Sim & Abandonou \\
\hline Canadá & Sim & Não \\
\hline Alemanha & Sim & Sim \\
\hline Catar & Não & Abandonou \\
\hline Grécia & Sim & Sim \\
\hline Índia & Não & Sim \\
\hline Lituânia & Não & Abandonou \\
\hline Republica Checa & Sim & Abandonou \\
\hline Turquia & Sim & Abandonou \\
\hline Eslováquia & Sim & \\
\hline
\end{tabular}

Fonte: GAO - Unite States General Accounting Office, Novembro de 2003

\section{PESQUISA REALIZADA COM EXECUTIVOS E COM AUDITORES}

A complexidade do tema "Rodízio de firmas de Auditoria" e a diversidade de opiniões a respeito de sua aplicabilidade nos diversos segmentos que compõem o mercado de capitais no Brasil, determinou a elaboração de uma pesquisa ${ }^{5}$ com os auditores independentes, representados por profissionais de firmas de Auditoria e por auditores pessoas físicas e com os executivos de empresas, representados pelos responsáveis pela elaboração das demonstrações contábeis, pelos profissionais que atuam em contato direto com os auditores e pelas pessoas em funções de controle de componentes estratégicos das demonstrações contábeis das empresas.

O objetivo da pesquisa é o de confirmar se o rodízio de firmas da Auditoria tem a capacidade de diminuir os riscos de perda de independência dos auditores e de evitar erros e fraudes na elaboração de um exame das demonstrações contábeis.

A amostra para os executivos foi determinada pelas 300 maiores empresas indicadas na Revista Exame e pelos 50 maiores Bancos brasileiros indicados na Revista Conjuntura Econômica. Foram obtidos 84 questionários de executivos que se colocaram à disposição para respondê-los. No que tange aos auditores independentes, foram enviados 70 questionários para profissionais que trabalham em 30 firmas de auditoria independente e obtidos 43 questionários respondidos. Dessa amostra, os profissionais solicitados a opinarem são categorizados em sócios de firmas, diretores, gerentes, supervisores, seniores e assistentes.

A pesquisa foi efetuada de 15 de maio a 30 de junho de 2004, e os principais resultados estão assim apresentados:

Confirmou-se que os auditores alteraram a forma de trabalhar nos clientes. O foco adicional aos trabalhos vem enfatizando o conhecimento do ambiente de controles internos e a identificação de fraudes contábeis nas empresas, com novos procedimentos de auditoria focados em fraudes.

É importante destacar que a pesquisa confirmou que os auditores se sentem mais à vontade não atuando como consultores. Essa posição já reflete uma pressão externa regulatória. A cultura do auditor-consultor tem-se reduzido, não por iniciativa das firmas, mas pela consciência de quem contrata.

O conhecimento acumulado pelo auditor na empresa é considerado um ponto fundamental para os clientes. As opiniões identificaram problemas de eficiência nos primeiros anos de auditoria. Os auditores sentem-se mais eficientes quando conhecem os controles internos e o segmento de atuação do cliente. A posição similar dos entrevistados confirma que é fundamental o conhecimento acumulado no processo de auditoria.

Foi discrepante a diferença de visão em relação a fraudes contábeis. Nesse tópico, as partes apresentaram vi-

5 Pesquisa realizada entre maio e julho de 2004 para fundamentar a dissertação de mestrado sobre o tema "Rodízio de Firmas de Auditoria". 


\begin{tabular}{|l|c|c|}
\hline \multicolumn{1}{|c|}{ Afirmaçães dirigidas aos executivos } & $\begin{array}{c}\text { Concorda } \\
\text { (\%) }\end{array}$ & $\begin{array}{c}\text { Discorda } \\
\text { (\%) }\end{array}$ \\
\hline Forma de trabalhar dos auditores mudou após os escândalos coorporativos & 85 & 15 \\
\hline Troca de auditores deve ser definida pelo órgão regulador & 52 & 48 \\
\hline Os auditores não devem atuar como consultores de seus clientes & 63 & 37 \\
\hline Não devem ser utilizados profissionais sem experiência nas equipes de auditoria & 55 & 45 \\
\hline Auditores recém-contratados são pouco eficientes em seu trabalho. & 65 & 35 \\
\hline Os erros contábeis aumentam com a relação de longo prazo do auditor e cliente & 46 & 54 \\
\hline Troca constante de staff aumenta a qualidade dos trabalhos & 25 & 75 \\
\hline Mudar a firma de auditoria gera maior sensação de independência & 58 & 42 \\
\hline Existem situações de conflito de interesses em trabalhos feitos por auditores & 75 & 25 \\
\hline O rodízio de firmas de auditoria & 66 & 34 \\
\hline
\end{tabular}

Quadro 3 Pesquisa realizada com executivos de empresas

\begin{tabular}{|l|c|c|c|}
\multicolumn{1}{|c|}{ Afirmações } & $\begin{array}{c}\text { Muito } \\
\text { importante } \\
\text { (\%) }\end{array}$ & $\begin{array}{c}\text { Importante } \\
\text { (\%) }\end{array}$ & $\begin{array}{c}\text { Pouco /sem } \\
\text { importância } \\
\text { (\%) }\end{array}$ \\
\hline O conhecimento acumulado do auditor & 54 & 41 & 5 \\
\hline Mudanças de sócios gera nova visão nos trabalhos & 31 & 52 & 17 \\
\hline Auditor deve identificar fraudes e erros contábeis & 82 & 18 & 0 \\
\hline A empresa de auditoria deve ter Código de Ética & 71 & 19 & 10 \\
\hline Governo deve quebrar a concentração do mercado de auditoria & 25 & 16 & 59 \\
\hline Departamentos de monitoramento de problemas de independência & 76 & 23 & 1 \\
\hline Presença de sócios e gerentes em campo. & 55 & 35 & 10 \\
\hline Uma nova forma de trabalho de auditoria é requerida. & 39 & 47 & 14 \\
\hline
\end{tabular}

Quadro 4 Pesquisa realizada com executivos de empresas

\begin{tabular}{|l|c|c|}
\multicolumn{1}{|c|}{ Pergunta } & Sim (\%) & Não (\%) \\
\hline Foi modificada a forma de trabalhar dos auditores após os escândalos? & 74 & 26 \\
\hline A perda compulsória do cliente altera a forma de trabalho? & 51 & 49 \\
\hline A atualização técnica disponível no mercado é suficiente para os auditores? & 38 & 62 \\
\hline Auditor deve atuar como consultor em clientes de auditoria? & 34 & 66 \\
\hline A utilização de profissionais menos experientes aumenta o risco do trabalho? & 33 & 67 \\
\hline Preço de um serviço de auditoria é compatível com a responsabilidade? & 14 & 86 \\
\hline Conhecimento acumulado gera maior eficiência nos trabalhos? & 84 & 16 \\
\hline Erros contábeis são identificados pelo auditor? & 83 & 17 \\
\hline Prática e normas de auditoria são capazes de identificar fraudes contábeis? & 39 & 61 \\
\hline Governo deve atuar na concentração de mercado de auditoria? & 19 & 81 \\
\hline Favorável ao rodízio de firmas? & 22 & 78 \\
\hline Favorável ao rodízio de profissionais? & 71 & 29 \\
\hline
\end{tabular}

Quadro 5 | Pesquisa realizada com auditores

sões completamente distintas em relação ao assunto. As empresas consideraram essencial a identificação de fraudes pelas firmas de auditoria, e os auditores confirmaram que os procedimentos que executam nos exames de auditoria não são capazes de identificar fraudes.

Os procedimentos de auditoria são direcionados para que as demonstrações contábeis estejam adequadamen- te apresentadas, portanto, muito distantes dos procedimentos de identificação de fraudes contábeis, nos quais a relevância não é levada em consideração e a forma de atuação é completamente distinta do padrão de auditoria atual. Desse modo, a presença de mais auditores seniores em campo foi requerida pelos executivos das empresas. 


\section{CONCLUSÃO}

O estudo não confirma a efetividade do rodízio como uma medida que visa à emissão de demonstrações contábeis mais adequadas e reais e a realização de exames de auditoria mais eficazes nas empresas.

A independência do auditor, a questão ética identificada nas fraudes, foi estudada no contexto da formação do valor ético pessoal e sob a ótica do relacionamento do auditor com o cliente. A determinação de prazos para diminuir o relacionamento pessoal e profissional de longo prazo entre firmas de auditoria e clientes não extingue a possibilidade de falhas e erros no trabalho do novo auditor.

A formação ética, o histórico moral e, principalmente, a estrutura emocional como pessoa serão os atributos que definirão se o auditor aceitará conviver com situações que possam ser consideradas inadequadas dentro do campo da Contabilidade e das normas de Auditoria Independente.

As propostas inadequadas de funcionários a auditores, ocorrências de fraudes corporativas e erros contábeis, tentativas de suborno, omissão de informações financeiras ao mercado e outras situações similares podem acontecer em um relacionamento de poucos meses, 2 anos, 20 anos ou até 50 anos. Os anos de relacionamento não interferem na conduta pessoal. A perda de independência decorre da perda da integridade e da objetividade, padrões comportamentais e de fundo mental que são inerentes a cada pessoa.

O estudo identifica várias pesquisas com evidências de aumento de erros cometidos nos primeiros anos de relacionamento do novo auditor, quando esse ainda não tinha todo o conhecimento requerido para auditar a companhia.

$\mathrm{Na}$ pesquisa local, o aspecto do "conhecimento acumulado" do auditor na empresa foi considerado fundamental pelos clientes que constataram procedimentos de auditoria pouco eficientes nos primeiros anos de relacionamento. Em igual sentido, a quase totalidade dos auditores sentese mais eficiente quando conhece os controles internos e o segmento de atuação do cliente.

A diferença de visão entre executivos e auditores em relação a fraudes é relevante e preocupante. As empresas consideraram essencial a identificação de fraudes pelas firmas de Auditoria e os auditores confirmaram que os procedimentos que executam nos exames de auditoria não são capazes de identificar fraudes.
Os procedimentos de auditoria são direcionados para que as demonstrações contábeis estejam fidedignamente apresentadas de acordo com os princípios de contabilidade geralmente aceitos, portanto, muito distantes dos procedimentos específicos, utilizados na identificação de fraudes, nos quais a relevância e materialidade não são levadas em consideração e a forma de trabalho é completamente distinta do padrão de auditoria atual. Tal fato é salientado na pesquisa local com auditores, na confirmação de que as normas de Auditoria não são capazes de identificar fraudes e pela grande solicitação de presença de auditores mais experientes no ambiente corporativo das empresas.

O estudo confirma que os riscos de fraude e de erros contábeis são aumentados no processo de auditoria das demonstrações contábeis das empresas quando se adota o rodízio de firmas. A pouca convivência do auditor com o ambiente interno de seu cliente, a baixa exposição à cultura corporativa e o fato de não atuar diretamente no processo produtivo aumenta os riscos para entendimento e crítica do ambiente de controles internos das entidades.

As pesquisas internacionais e locais sobre fraudes e sobre corrupção empresarial confirmaram a pouca competência dos auditores externos na identificação de fraudes. Ademais, como aspecto negativo, foi confirmado que a educação continuada, disponibilizada aos auditores e contadores, não abrange o conceito de fraudes na intensidade solicitada pelo mercado.

Assim, mesmo com a troca de auditores, se não houver um foco específico no seu treinamento e na mudança das normas de Auditoria para a identificação de fraudes, é certo que, com ou sem o rodízio, processos fraudulentos devem continuar nas empresas.

Apesar das opiniões favoráveis e contrárias ao rodízio, o estudo confirma que os aspectos inerentes à natureza humana na vida corporativa e no mundo dos negócios, dimensionados na cobiça, na ambição e na vaidade, são características comuns às pessoas e potencializados no dia a dia do trabalho e em determinadas ocasiões, pode fazer prevalecer o interesse pessoal em detrimento do interesse público. Nessas circunstâncias, não há auditoria que esteja livre de erros, fraudes e substituições de firmas de Auditoria. 


\section{Referências}

AICPA - American Institute of Certified Public Accountants. Statement of Position Regarding Mandatory Rotation of Audit Firms of Publicly Held Companies. Emitida em 1992. Disponível em: <www.aicpa.org/members/div/secps/lit/sops/1900.htm>.

ANTUNES, J. Contribuição ao estudo de Avaliação de Risco e Controles Internos na Auditoria de Demonstraçães Contábeis no Brasil. Dissertação (Mestrado) - Faculdade de Economia e Administração da Universidade de São Paulo, São Paulo, 1998.

ARISTÓTELES. Ética a Nicômaco. Texto integral traduzido por Pietro Nassetti. São Paulo:Martin Claret, 2004.

ASSOCIATION OF CERTIFIED FRAUD EXAMINERS 2004. Report to the Nation on Occupational Fraud and Abuse. Disponível em: <www. cfenet.com>.

BENTHAM, J. Capítulo 1. Princípio da Utilidade. Princípios da Moral e da Législaçà̀o. Editora Prometeus, 1988.

BOYNTON, W C; JOHNSON, R. N.; KELL, W. G. Auditoria, Tradução da 7ª edição do original Modern Auditing por José Evaristo dos Santos. São Paulo: Atlas, 2002.

CGAA - Co-Ordinating Group on Audit and Accounting Issues: Final Report, To the Secretary of State for Trade and Industry and the Chancellor of the Exchequer. 29 jan. 2003. Disponível em: <www.dti.gov.uk/cld/cgaai-final.pdf>.

CHEW Ng. Rotation of Auditors: History and Recent Developments. School of Accounting; Banking \& Finance. Logan Campus. Griffith University, University Drive, Meadowbrook, Australia 4131.2003. Disponível em: <http://www.unisi.it/>.Acesso em: 22 jan. 2004.

FERREL, O. C.; FRAEDRICH, J.; FERREL, L. Ética Empresarial: Dilemas, tomadas de decisões e casos. 4 ed. Rio de Janeiro: Reichmann \& Affonso Editores, 2000.

GAO - United States General Accounting Office. Report to the Senate Committee on Banking, Housing, and Urban Affairs and the House Committee on Financial Services. Public Accounting Firms: Required Study on the Potential Effects of Mandatory Audit Firm Rotation. Nov. 2003. Disponível em: <http://www.gao.gov $>$.

IBRACON - Instituto dos Auditores Independentes do Brasil. Carta enviada em 17 de março de 2003 à CVM - Comissão de Valores Mobiliários, ao.Sr. Luis Leonardo Cantidiano. Boletim do IBRACON na edição de abr.-mai.-jun. 2003 com o nome Rodízio de Firmas de Auditoria. Disponível em: <www.ibracon.com.br >

IFAC - International Federation of Accounting - Code of Ethics. Seção 8 - Independência. Aprovado em nov. 2001. Disponível em: $<$ http://www. ifac.org>.

KANT, I. Crítica da Razão Prática. São Paulo: Martin Claret, 2004.

KPMG - A fraude no Brasil. Relatório da pesquisa 2004. Disponível em: <www.kpmg.com.br $>$ em 04/03/2005.

LISBOA, L. P. Ética Geral e Profissional em Contabilidade. 2 ed. FIPECAFI; USP. São Paulo: Atlas, 1997.

NEPONUCEMO, V. A queda da contabilidade gerencial e a ascensão da fraude contábil nos Estados Unidos. Disponível em: <www.monografias. com>. Acesso em: 3 mar. 2002.

RASMUSSEN, V. W. Desvios, desfalques e fraudes nas transaçốes de compras nas empresas: uma análise transnacional da aplicação dos controles internos na atividade de administração de materiais. São Paulo: Aduaneiras, 1988.

SÁ, A. L. Ética profissional. 4 ed. rev. e ampliada. São Paulo: Atlas, 2001.

SDA UNIVERSITÀ BOCCONI, Corporate Finance and Real Estate Dept. And Administration and Control Dept. The Impact of Mandatory Audit Rotation on Audit Quality and on Audit Pricing: the case of Italy, 2002.

SEC - Securities and Exchange Commission. Discurso de Jackson M. Day, Acting Chief Accountant US. Securities and Exchange Commission. Speech before the New York State Society of Certified Public Accountants, 28 jan. 2003.

SEC - Securities and Exçhange Commission. Final Rule: Auditor Independence. 5 fev. 2001.

TRANSPARÊNCIA BRASIL. Corruption in Brasil: Perspective from the private sector, 2003. Disponível em: <www. Transparenćia.org.br> Acesso em: abr. 2004

VAMPEL, D. Gestã̃o sob prova da SEC. Revista Capital Aberto, p. 26, jul: 2004

\section{NOTA - Endereço dos autores}

Faculdade São Luís

Rua Haddock Lobo, 400

Cerqueira César - Sã̃o Paulo

01414-902
Pontifícia Universidade Católica de São Paulo Rua Ministro de Godói, 969 - 4 Andar Ed. Bandeira de Mello - Perdizes - São Paulo - SP 05015-001 